\title{
Targeting Herpetic Keratitis by Gene Therapy
}

\author{
Hossein Mostafa Elbadawy, ${ }^{1}$ Marine Gailledrat, ${ }^{2}$ Carole Desseaux, ${ }^{2}$ \\ Diego Ponzin, ${ }^{1}$ and Stefano Ferrari ${ }^{1}$ \\ ${ }^{1}$ The Veneto Eye Bank Foundation, Via Paccagnella 11, Padiglione Giovanni Rama, Zelarino, 30174 Venice, Italy \\ ${ }^{2}$ Cellectis Therapeutics SAS, 8 rue de la Croix Jarry, 75013 Paris, France
}

Correspondence should be addressed to Hossein Mostafa Elbadawy, hossein.elbadawy@fbov.it

Received 31 May 2012; Accepted 30 November 2012

Academic Editor: Pierre Lachapelle

Copyright (C) 2012 Hossein Mostafa Elbadawy et al. This is an open access article distributed under the Creative Commons Attribution License, which permits unrestricted use, distribution, and reproduction in any medium, provided the original work is properly cited.

\begin{abstract}
Ocular gene therapy is rapidly becoming a reality. By November 2012, approximately 28 clinical trials were approved to assess novel gene therapy agents. Viral infections such as herpetic keratitis caused by herpes simplex virus 1 (HSV-1) can cause serious complications that may lead to blindness. Recurrence of the disease is likely and cornea transplantation, therefore, might not be the ideal therapeutic solution. This paper will focus on the current situation of ocular gene therapy research against herpetic keratitis, including the use of viral and nonviral vectors, routes of delivery of therapeutic genes, new techniques, and key research strategies. Whereas the correction of inherited diseases was the initial goal of the field of gene therapy, here we discuss transgene expression, gene replacement, silencing, or clipping. Gene therapy of herpetic keratitis previously reported in the literature is screened emphasizing candidate gene therapy targets. Commonly adopted strategies are discussed to assess the relative advantages of the protective therapy using antiviral drugs and the common gene therapy against long-term HSV-1 ocular infections signs, inflammation and neovascularization. Successful gene therapy can provide innovative physiological and pharmaceutical solutions against herpetic keratitis.
\end{abstract}

\section{Introduction}

Gene therapy is the experimental use of genetic manipulation techniques to correct errors associated with genetic diseases or to modify undesirable Deoxyribonucleic acid (DNA) sequences. The ever extending list of genetic diseases opens the door wide to gene therapy as a new hope for targeting the aetiology rather than the symptoms of these diseases. Plenty of disciplines of gene therapy are currently discussed in the literature. However, there is a general agreement on few main issues to be thoroughly addressed before commencing a clinical trial for a novel gene therapy. Those include the precise diagnosis of the addressed genetic error, the relation between the causative gene defect and the resultant disease, the specific targeted tissue in the body, the dosage form design, and the choice of route of administration. Gene therapy approaches to corneal pathological disorders are being studied extensively to provide much needed progress against specific corneal malfunctions. Unlike protein based therapy, gene therapy has more research-attractive benefits being cheaper, better controlled, and more efficient in many occasions.

Herpes simplex virus type 1 (HSV-1) is a widespread human pathogen that causes life-long recurring disease. Two HSV serotypes exist, HSV-1 and HSV-2, with distinct tropism reported for each. The cold sore virus (HSV-1) is a leading cause of corneal blindness [1] and rejection of corneal grafts in the developed world [2]. The worldwide seroprevalence rates of HSV-1 ranges from 50 to $90 \%$ [3]. Most of the population acquires the infection during early age and adolescence. Both serotypes are reported to infect the cornea and the neural cells too. However, the vast majority of HSV infections in the eye are caused by HSV-1 serotype. Soon after the HSV-1 infection, the virus develops lifelong latency in the sensory ganglion of the trigeminal nerve (trigeminal ganglion) as confirmed in several reports [4-7]. When active, HSV-1 travels from the trigeminal ganglion to different destinations, including the cornea. However, there is a growing body of evidence suggesting that the virus may 
be able to remain in its quiescent stage within the stroma [810]. Acyclovir and corticosteroids are normally prescribed either alone or in combination for common HSV keratitis [11]. For example, prednisolone drops with prophylactic oral antiviral drug is common in stromal keratitis. The treatment of recurrent epithelial keratitis includes cycloplegia as well as antiviral eye drops such as trifluridine.

By November 2012, the online record gene therapy clinical trials worldwide provided by the Journal of Gene Medicine (http://www.abedia.com) shows 28 currently active clinical trials addressing different ocular diseases, such as age-related macular degeneration, choroideraemia, and glaucoma [12]. Interestingly, recent progress has been made targeting HSV-1 genome, as a new anti-viral class of medications $[13,14]$. In this article, we review the current situation of ocular gene therapy against HSV-1 infections, including viral and non-viral vectors, routes of delivery of therapeutic genes and targets by screening and analyzing publications on ocular gene therapy from the published literature, and identify promising pathways, new techniques, and crucial research ideas. We also examine the advancements and prospects of ocular gene therapy, the progress and inadequacies, with potential solutions in this field of research. Targeting the genome of HSV-1 is a promising novel strategy in gene therapy field, and is the focus of this paper.

\section{Background}

2.1. Biology of HSV-1. HSV-1 belongs to the human herpes virus (HHV) family. The HSV-1 virion is $120-300 \mathrm{~nm}$ in size. The genetic material of HSV-1 comprises 152,000 base pairs (encoding more than 80 genes) arranged as a double-stranded DNA, which circularizes upon infection [15]. The genetic material is surrounded by a capsid of a $100 \mathrm{~nm}$ diameter, a tegument and an envelope. The capsid of the HSV-1 virus is unique; the icosadeltahedral capsid is composed of 162 capsomers, surrounded by an amorphous structure containing various proteins and enzymes. The tegument surrounding the capsid contributes to the virulence of the virus. The virion is surrounded by a lipid bilayer envelope, acquired from the host, with 12 embedded glycoproteins. These glycoproteins function as attachment, fusion, structural and anti-immune proteins (Figure 1(a)). Five of these glycoproteins $(\mathrm{gB}, \mathrm{gC}, \mathrm{gD}$, and the complex of gH and gL) mediate the entry of HSV-1 into host cells. Three dimensional structures revealed using cryoelectron tomography showed that the tegument was asymmetric where the capsid was more close to the envelope from one side. On the other side, they were distanced by $\sim 35$ nanometers of tegument [16]. The HSV-1 genome consists of a linear, double-stranded DNA molecules of $152 \mathrm{~kb}$ containing more than 80 genes and is composed of long $(\mathrm{L})$ and short $(\mathrm{S})$ unique $(\mathrm{U})$ sequences regions $\left(\mathrm{U}_{L}\right.$ and $U_{S}$ resp.), which are flanked by regions of internal and terminal repeats. Those unique sequences are combined with specific origins of replication for each. Those repeats includes terminal repeat (TR) of long $\left(\mathrm{TR}_{L}\right)$ and short segment $\left(\mathrm{TR}_{S}\right)$, internal repeat (IR) of the long segment $\left(\mathrm{IR}_{L}\right)$ and short segment $\left(\mathrm{IR}_{S}\right)$. The sequences surrounding $U_{L}$ region are labelled $a b$ and $b^{\prime} a^{\prime}$ while those around the $U_{S}$ region $a^{\prime} c$ and ca, see Figure 1(b). Around half of the genome sequences are conserved; however, mutations in other half of the genes have been reported not to affect the replication process. HSV1 genome also contains a pac signalling sequence, essential for packing the DNA into the viral capsid [1].

2.2. Latency Mechanisms. During the latency stage of the HSV lifespan, the expression of latency-associated transcripts (LATs) is switched on, while general gene expression is restricted. Exit of the dormancy state can be triggered by decreased immunity due to infection, stress, ultra violet (UV) radiation or fever. The conjunctiva is believed to be the first affected organ by active HSV-1 infection [1]. Viral replication in the trigeminal ganglia continues until CD8+ (Cluster of differentiation 8) T-cell activity increases and the DNA mending mechanism cause the latency of the virus $[17,18]$.

2.3. Diagnosis of the Infection. Regarding the fact that asymptomatic HSV-1 infection is widespread, the diagnosis of HSV-1 through clinical symptoms is questionable. Laboratory methods performed by a specialized virologist is highly recommended [19]. The commonly used methods include direct fluorescence antibody test, polymerase chain reaction (PCR) and cell culture using Vero cell line. However, direct fluorescence antibody test was reported to have superior sensitivity than PCR. Both methods had better sensitivity than the cell culture method, however, PCR showed higher degree of specificity [20]. Using antibodies against HSV-1 is a highly recommended method [21]. Recently, another group has shown that PCR and fluorescence antibody test have equal sensitivity: comparing specimens taken from cornea (by scraping) or from the patient's tears, results from PCR and fluorescence antibody test had similar sensitivity and negative predictive figures [22].

2.4. Clinical Management. Treatment of HSV-1 cases typically combines medications such as inflammation, immune and neovascularisation suppressing agents together with an anti-viral drug. Corticosteroids are used to improve clinical signs due its anti-inflammatory and antiangiogenesis effects. Several antiviral drugs have shown efficacy in the treatment of ocular HSV-1 keratitis, including acyclovir, valacyclovir, cidofovir, trifluorothymidine, and ganciclovir [23-25]. First line therapy for HSV-1 is acyclovir or valacyclovir $[1$, $26,27]$. Epithelial infection is usually treated with $3 \%$ acyclovir ointment for two weeks, while stromal necrotizing or non-necrotizing infections are treated with acyclovir in combination with a corticosteroid $[28,29]$. Yet, resistance to acyclovir has recently been reported [30-32]. Therefore, novel antiviral drugs are highly demanded. Ganciclovir (as $0.15 \%$ gel) activity was established in the first case series describing effective treatment and prophylaxis of herpetic keratitis [33]. The commonly prescribed antiviral and corticosteroids drugs only alleviates the symptoms and shortens the infection period, but it does not prevent the reactivation 


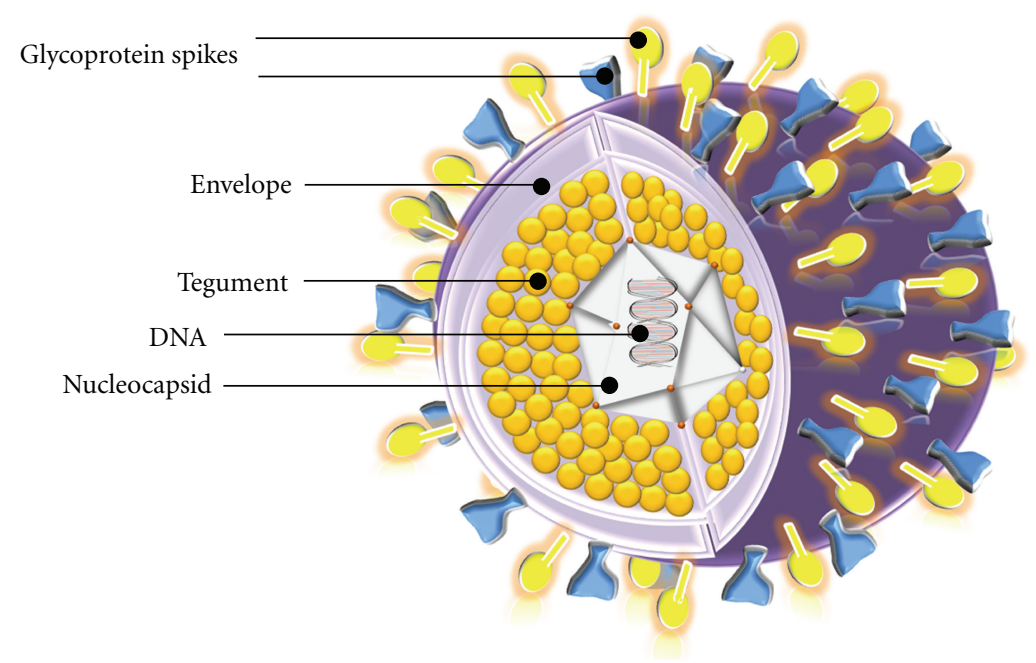

(a)

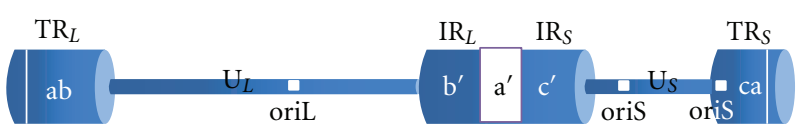

(b)

FIGURE 1: HSV-1 model structure and genome arrangement. (a) The icosahedral, DNA-containing capsid is asymmetrically located within the virion and surrounded by an amorphous protein layer called the tegument, and a membrane envelope heterogeneously studded with morphologically distinct spikes formed by 12 different glycoprotein species. (b) The HSV-1 genome arrangement showing repeats surrounding $U_{L}$ designated $a b$ and $b^{\prime} a^{\prime}$, and those surrounding $U_{S}$ designated $a^{\prime} c^{\prime}$ and $c a$. There are two different origins of replication, oriL in the long segment and oriS in the short segment. Abbreviations: $\mathrm{U}_{L}$ : long unique sequence; $\mathrm{U}_{S}$ : short unique sequence; $\mathrm{TR}_{L}$ : terminal repeats of long segment; $\mathrm{TR}_{S}$ : terminal repeats of short segment; $\mathrm{IR}_{L}$ : internal repeat of the long segment; $\mathrm{IR}_{S}$ : internal repeat of short segment.

of latent infections, consequently raises the demand for a new class of innovative powerful and safe genetic antiviral drugs. However, long-term administration of Acyclovir can help decrease the recurrence of the infection. Although few studies are discussing the possibility of producing a vaccine against both HSV serotypes [34, 35], the potential of treating ocular diseases using gene therapy is now more feasible. Gene therapy has the advantages of prolonged therapeutic effect, tissue-type specificity, transcriptional control via specific regulatory elements [36].

2.5. Immune Response to HSV-1 Infection. Understanding the mechanisms by which HSV-1 can survive or overcome the host immunity is a gateway for the development of novel antiviral therapies. Primarily, complex anti-viral defence mechanisms based on innate and adaptive immunity activates immune recruitment mechanisms. An immune cascade, orchestrated mainly by T-cells, is responsible for the pathogenesis of HSV-1. Other antiviral resistance molecules, grouped under "intrinsic antiviral immunity", have recently emerged as a promising class in virus-battling research field [37]. Viral replication and assembly can be directly interrupted by preexisting agents in the host cell. Intrinsic factors, such as restriction factors, directly impede the normal viral lifespan [38].

\section{Gene Transfer Vectors for Corneal Gene Therapy}

Three approaches of gene transfer have been considered. The first one is systemic administration, even if the wide spread distribution in the host body is a major concern. Moreover, the gene delivery to the trigeminal ganglion where the HSV-1 latency requires high specificity and crossing the blood brain barrier to nerves. Second is the local application of naked therapeutic gene or a loaded vector. The third approach is to treat the cornea ex vivo where corneas can be treated prior to surgery. The main advantage here is safety and accessibility to the endothelium, even if the gene transfer can be performed only once.

The vectors must be chosen and modified to safely and efficiently escort DNA from outside the cell to the nucleus and to overcome several physical barriers that are obstacles to internalization, escape from endocytotic vesicles, movement through the cytoplasm, and transport into the nucleus. Vehicles for ocular gene therapy have been described in a broader prospect in number of reviews, therefore is not the focus of this paper. Nonetheless, here we attempt to fill the gaps, concentrate on the latest advances, and set up future directions for each vector type that can be used for corneal gene therapy of corneal herpetic keratitis. 
Most clinical trials for ocular gene therapy utilized viral vectors for gene delivery [12]. No record exists for clinical trials on herpetic keratitis gene therapy. Four classes of viruses are reportedly used in ocular gene therapy; those are adenovirus, adeno-associated virus, retrovirus, and lentivirus vectors. Nevertheless, the use of adenovirus and retrovirus was limited due to the relatively high inflammatory reactions of these viruses, plus their inability to transduce the all layers of the cornea, especially the endothelium [39].

Adenovirus. Ex vivo transduction of human corneas with adenoviral vectors containing lacZ reporter gene under either cytomegalovirus (CMV) or Rous sarcoma virus (RSV) transcriptional promoters provided high transduction efficiency especially in the endothelium [40]. Various approaches have been developed to modify adenovirus tropism. Changes have been introduced to adenovirus vectors to lower their immunogenicity. For example, the modification of the capsid protein polymers such as polyethylene glycol (PEG) extends circulation kinetics in murine models to allow neutralization of the adenovirus vectors by antibodies. The activated PEG reacts preferentially with the $\varepsilon$-amino termini of lysine residues on the capsid, specifically the hexon, fiber, and penton base proteins, resulting in improved specificity and lowered toxicity [41]. Moreover, the incorporation of a laminin derived peptide to a polymer modified adenovirus can improve its cell-type targeting specificity [42]. Several modifications can be introduced to adenovirus to improve its performance in gene therapy, approaches are discussed in a recent review [43]. Also adeno/HIV (human immunodeficiency virus) or adeno/AAV (adeno-associated virus) hybrids have been developed [44-46].

Adeno-Associated Virus. The current leading choice for corneal gene therapy is the adeno-associated virus (AAV). The expression pattern of this virus shows a delayed expression of the transgene; therefore, the therapeutic activity can be sustained for many years [47]. Recombinant AAV was successfully used to deliver therapeutic molecules to whole-thickness rabbit and human corneas ex vivo [48, 49]. Gene therapy using AAV vector to decrease corneal neovascularisation associated with corneal HSV-1 infections is reviewed elsewhere [39]. Recently, novel modifications to the viral genome and capsid were introduced to optimise the efficiency and tropism of AAV vectors. The genome of the new generation of self-complementary AAV vectors contains a covalently bound hairpin to form a duplex DNA molecule. The power point here is that self-complementary AAV vectors are no longer dependent on the host cell to convert the single-stranded AAV genome into transcriptionally active double-stranded forms. Self complementary AAV has shown a shorter lag time and believed to be a safer choice [5053]. Additionally, the production of hybrid "pseudotyped" rAAV vectors, where rAAV genome is packaged in a capsid of another AAV serotype is verified in many reports and can improve tissue specificity and reduce toxicity and inflammatory reactions $[54,55]$. The outcome of this mix and match process will not be reviewed here, as it is covered by others [54-56]. New comparative studies between different AAV serotypes for the transduction of human corneas (ex vivo) using intra-stromal injection was recently described [57]. Adeno/AAV hybrid vectors were shown to promote sitespecific integration to avoid the activation of oncogenes after the integration of the transgene into human genome $[44,45]$.

Lentivirus and Retrovirus. Lentivirus and retrovirus belong to the group Retroviridae. Lentivirus based vectors is a popular choice for gene delivery to the endothelium, as it is known to proficiently transduce slow dividing cells. This class of viral vehicles has been shown to competently transduce primary human endothelial cells with 30\% efficiency [58]. However, this property renders them unsuitable for stromal herpetic keratitis. On the contrary, successful lentivirus short hairpin RNA (ribonucleic acid) delivery to the cornea was used in a recent study, where a decrease in HSV-1 induced angiogenesis in stromal keratitis was observed [59]. Additionally, lentivirus was used for conveying therapeutic genes to improve corneal allograft endurance ex vivo [60].

The transduction efficiency of AAV can be improved by several methods, for example, creating a pocket with $110 \mu \mathrm{m}$ depth using femtosecond laser was shown to improve the efficiency of the lentivirus transduction of the stromal keratocytes, which is a promising method for antiangiogenesis agents that can improve the vision quality for HSV-1 after corneal transplantation [61].

Retrovirus (and lentivirus) genome is single stranded RNA, encapsulated in a lipid envelope. The name retro comes from its property of retro-transcription in linear double strand DNA to integrate into the host genome. Retroviral vectors recommended for transducing the cornea are based on different lentiviruses like HIV, equine infectious anaemia virus (EIAV) or feline immunodeficiency virus (FIV). The ability of retrovirus to transduce human corneas was confirmed in several report $[62,63]$. Yet, they are not able to infect slow or non-dividing cells, hence cannot be used for endothelium transduction [64]. On the other hand, microRNA was successfully transduced in corneal epithelial cells as recently reported [65].

Retroviral vectors are well known to integrate their genome into the host to achieve stable transgene expression. This property is useful when treating chronic HSV-1 infection because of the long lasting gene expression benefit. Genes can be delivered to the endothelium by injection into the anterior chamber of the eye. Most retroviral vectors are genetically modified to isolate the cis sequences, required for the transfer of viral genome, from the trans sequences that encode viral proteins to produce replication incompetent vectors [66]. However, if recombination events generate a replicative virus, it is a main safety concern due to the pathogenic nature of HIV.

Naked DNA. Neovascularisation resulting from HSV-1 immuno-stimulation causes severe vision opacity. An early study showed that the transfer of naked complementary DNA (cDNA) encoding the vascular endothelial growth factor (VEGF) receptor antagonist to the eye was shown to 
block the formation of blood vessels [67]. DNA has been shown to access the epithelium and stroma to be transcribed into angiogenesis-controlling drug [68]. Topical application of a DNA plasmid encoding interferon alpha 1 (IFN- $\alpha 1$ ) was effective against ocular HSV-1 neovascularisation in a time and dose dependent manner, and able to antagonize HSV-1 reactivation [69].

Microinjection. Intraocular injection of DNA plasmid encoding Interleukin 18 (IL-18) reduced angiogenesis and immunoinflammatory lesions resulting from HSV-1 infection of mice [70]. Delivery to the cornea by microinjection into different corneal tissue was described in several research reports [71-73]. Polylactic coglycolic acid (PLGA) nanoparticles were shown to be efficient, nontoxic, and sustainable form for gene therapy, progressively reducing murine [74] and rat [75] corneal neovascularisation.

Nanocarriers. Nanoparticles are used in many drug delivery systems. Hyaluronic acid and chitosan nanoparticles can be loaded with genetic medicines, RNAi or DNA plasmids and used for corneal gene therapy. Albumin nanoparticles were able to reduce neovascularisation by $40 \%$ after 5 weeks, with no significant toxicity [71]. Controlled release silica nanoparticles impregnated with antiviral drug against HSV-1 (acyclovir) were shown to be a promising approach, however, it was only tested in biosynthetic corneal transplants [76], and it is suggested to design a similar dosage form for gene therapy delivery to the cornea. Copolymers of poly lactic and glycolic acids (PGLA) nanoparticles are proved to be a good vehicle for gene therapy [74], and low molecular weight chondroitin sulphate/hyaluronan nanoparticles were shown to competently deliver a Green fluorescent protein (GFP) encoding plasmid to rabbit cornea [77].

Electroporation. Electroporation method employs high field strength, square-wave electric pulses to allow the penetration of therapeutics molecules. Genetic material or therapeutic molecules are applied to the surface of the cornea, and then the electric pulse will assist the diffusion process. While this method does not involve any biochemical agents and is therefore considered a safer choice, electroporation can cause severe cell damage and induce immunogenic reactions $[78,79]$. Alternatively, ultrasound can enhance gene transfer to mammalian corneal cells in vitro and in vivo without cell damage [80-82], and facilitates viral [83] and nonviral [84] gene and conventional drugs [81] delivery to the cornea. Electroporation was successfully used to deliver IL10 gene to mice corneas [85]. In vivo gene transfer to the endothelium [86] and stromal keratocytes [87] has been reported in rats. Nevertheless high voltage (more than 500V) can be hazardous.

Femtosecond Laser. Applications of the femtosecond laser are becoming more accepted in corneal refractive surgery and transplantation, due to high precision and safety, compared to conventional laser. The femtosecond laser can be used to create a pocket where in the corneal surface to assist the delivery of therapeutic agents. It was used to deliver the vector to the stroma [61] therefore is suggested to be used in chronic stromal herpetic keratitis conditions, if the latency of HSV-1 is in the stroma, as recently argued [9]. The femtosecond infrared titanium sapphire laser beam was shown to enhance in vivo gene delivery [88]. This method has been shown to effectively assist the closure of corneal neovascularisation in rabbits [89].

Synthetic Peptide Vector Systems. Antibody targeting can be a useful addition to the liposome gene transfer techniques. The use of antibodies with certain cell-specificities can be useful to target a specific corneal layer. Liposomes containing plasmid DNA and coated with antibodies will form an immuno-specific vector to target specific receptors of a given cell type, for example, targeting the endothelium to improve allograft survival $[90,91]$. Liposomes and transferrin (targeted to endocytic transferrin receptor) have been used successfully to modulate murine corneal allograft rejection with a therapeutic transgene. A vector system based on synthetic peptides of polylysine and molossin has been shown to deliver DNA plasmid to all rabbit cornea endothelial cells after direct application ex vivo [92].

Gene Gun. Gene gun method is also known as particle bombardment, microprojectile gene transferor gene gun. Ballistic transfer with the gene gun can be used to transfer cDNA coated gold particles to the epithelium [93]; however, the use of gene gun to transduce the endothelium was shown to severely damage [94].

Dendrimer and Liposome-Based Delivery. Dendrimers are macromolecules characterised by extensively branched three dimensional structure that can accommodate a genetic material, hence used for drug delivery. Activated polyamidoamine dendrimers carrying a DNA plasmid transduced up to $10 \%$ of corneal endothelium after direct application to the cornea [95]. Liposome gene transfer to the endothelium was reported [96]. The relative inefficiency of these vectors has limited their use in corneal gene therapy. However, polyethylene glycol-modified liposomes or the aid of ultrasound can improve the efficiency for drug delivery.

\section{Gene Therapy Strategies}

A body of work in gene therapy for corneal disorders has established the potential of finding new anti-HSV-1 gene therapy. Drug delivery to the cornea by gene therapy is preferably applied locally to avoid systemic complications, or performed ex vivo in an eye bank to improve the graft survival by prior to transplantation in a patient with herpetic keratitis history. Topical application may avoid modulation of the systemic immune response to HSV-1, and it is not likely to induce untoward corneal inflammation or systemic side effects. Several strategies have been used to target certain viral envelope component, replication process, protein, or the resultant inflammation. Most of the gene therapy work on herpetic keratitis was targeting the chronic inflammation 
process; however, less significant amount of data exists on targeting the virus genome.

4.1. Gene Therapy Targeting Inflammatory Mediators or Neovascularisation. Most of the gene therapy approaches to combat HSV-1 were directed to the inflammation process. In $20 \%$ of herpetic keratitis infections, when the latent virus is reactivated it results in chronic ocular immune response where specific lymphocytes are produced, mainly $\mathrm{CD}^{+} \mathrm{T}$ producing T-helper 1 (Th1) cytokines [97]. Herpetic stromal keratitis chronic inflammation causes edema, neovascularisation and scarring. Moreover, 5-10\% of cornea transplantation operations is performed to replace HSV1 damaged corneas [98]. Immunogenicity from herpetic keratitis infection can be reduced; however, reducing host sensitization is more preferable. A reasonable number of studies have been exploring the ability of gene therapy to deliver specific anti-inflammatory mediators, as briefed in Table 1, where successful attempts to target ocular HSV-1 by gene therapy are arranged in chronologic order to highlight the progress achieved. Reducing the inflammation and/or the neovascularisation will result in the desired regression of the herpetic keratitis signs. Additionally, survival rates of corneal allograft can also be improved. Nevertheless, it must be considered that the disease was masked and not actually cured. Therefore, the interest in the recent years was directed to the viral genome itself, as detailed in Section 4.2.

4.2. Gene Therapy Targeting the HSV-1 Genome. DNA damage response is a mechanism by which cells can correct damage or eliminate severely damaged cells by activating programmed cell death mechanisms. DNA damage mechanisms are involved in processes such as excision of the damaged area, cell cycle arrest to prevent the pass on of mutated sequences or the transcriptional level control. However, severe injuries can cause the cell to undergo apoptosis. The DNA repair mechanisms include direct repair, base excision repair, nucleotide excision repair, doublestrand break repair, and cross-link repair. Detailed description of these mechanisms is discussed elsewhere in more detail [125]. Understanding these mechanisms allows for the discovery of new genetic agents as possible antiviral candidates.

Targeting the HSV-1 genome for degradation, using several techniques have been reported, including the use of ribozymes [126], antisense oligodeoxy nucleotides [127], morpholino antisense nucleotides [128], small interfering RNA (siRNA) [117], aptamers [129], and homing endonucleases [130] (Figure 2).

Ribozymes. Ribozymes are RNA molecules with intrinsic enzymatic activity to promote a variety of reactions without the aid of protein cofactor, usually involving cleaving or splicing of RNA molecules, therefore, can be used for gene therapy [131]. They have been shown to be active against HIV-1 [132] and HSV-1 [126, 133], where it improved the survival rate in mice. Ribozymes are less potent than siRNA,

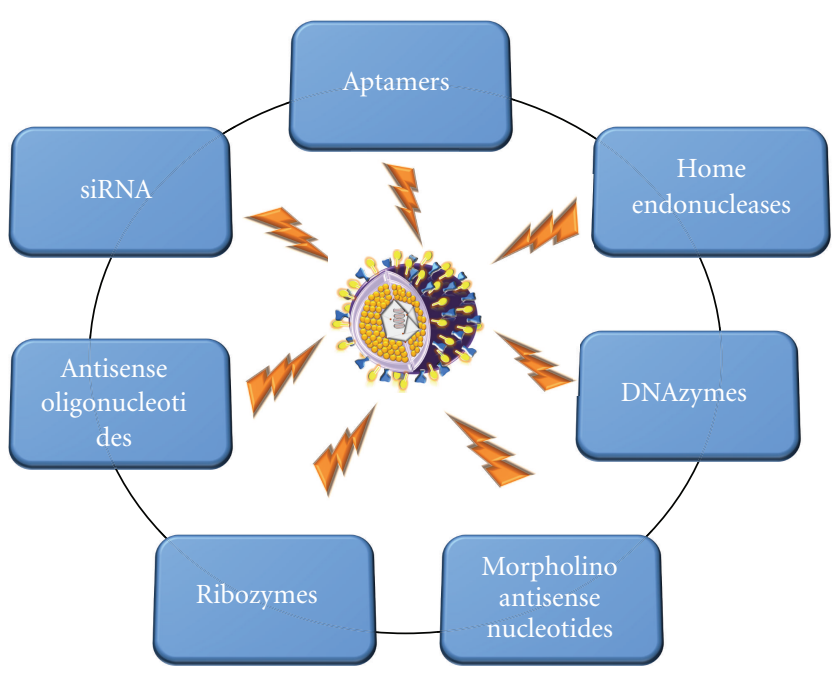

FIGURE 2: Successful targeting of HSV-1 genome by gene therapy to date. Abbreviations: DNAzymes: deoxyribozymes; siRNA: small interfering RNA; HSV-1: herpes simplex virus serotype 1 .

however, the evolution of new ribozymes and the relatively better specific binding are two advantages.

Antisense Oligodeoxynucleotides. Antisense oligodeoxynucleotides are short synthetic DNA consisting of 15 to 20 nucleotides. They inhibit protein biosynthesis by specifically targeting the complementary stretches of RNA. In principle, they are able to interfere with each step of nucleic acid metabolism, preferentially to block translation [134]. Antisense oligonucleotides were used against HSV-1 [127, 135], moreover, topical treatment was found to reduce TNF- $\alpha$ in cultured lymphocytes and in vivo in mice, but systemic administration was not successful [114]. However, the topical TNF- $\alpha$ blockade may interfere with the antiviral response, ultimately leading to recurrent herpetic keratitis.

Morpholino Antisense Oligonucleotides. As antisense oligonucleotides, morpholinos function by translational arrest. Phosphorodiamidate morpholino oligomers (PMOs) are a subclass of antisense oligonucleotides modified to include a phosphorodiamidate linkage and morpholine ring to demonstrate limited off-target effects, favourable base stacking, high duplex stability, high solubility, cell permeability, and no hybridization complexities [136]. In a recent promising study, targeting the translation sites ICP0 in HSV1 genome in mice with peptide conjugated PMO showed better inhibition than acyclovir [128].

Small Interfering RNA (siRNA). The ability of transfected synthetic siRNAs to suppress the expression of specific transcripts is a useful technique to probe gene function in mammalian cells. Plasmids encoding small hairpin RNAs are extensively used in gene therapy. Consequently, siRNA was used to target viruses in several studies [137-139]. Targeting neovascularisation resulting from herpetic keratitis, Kim et al., [117] have shown that siRNAs against VEGFA, 


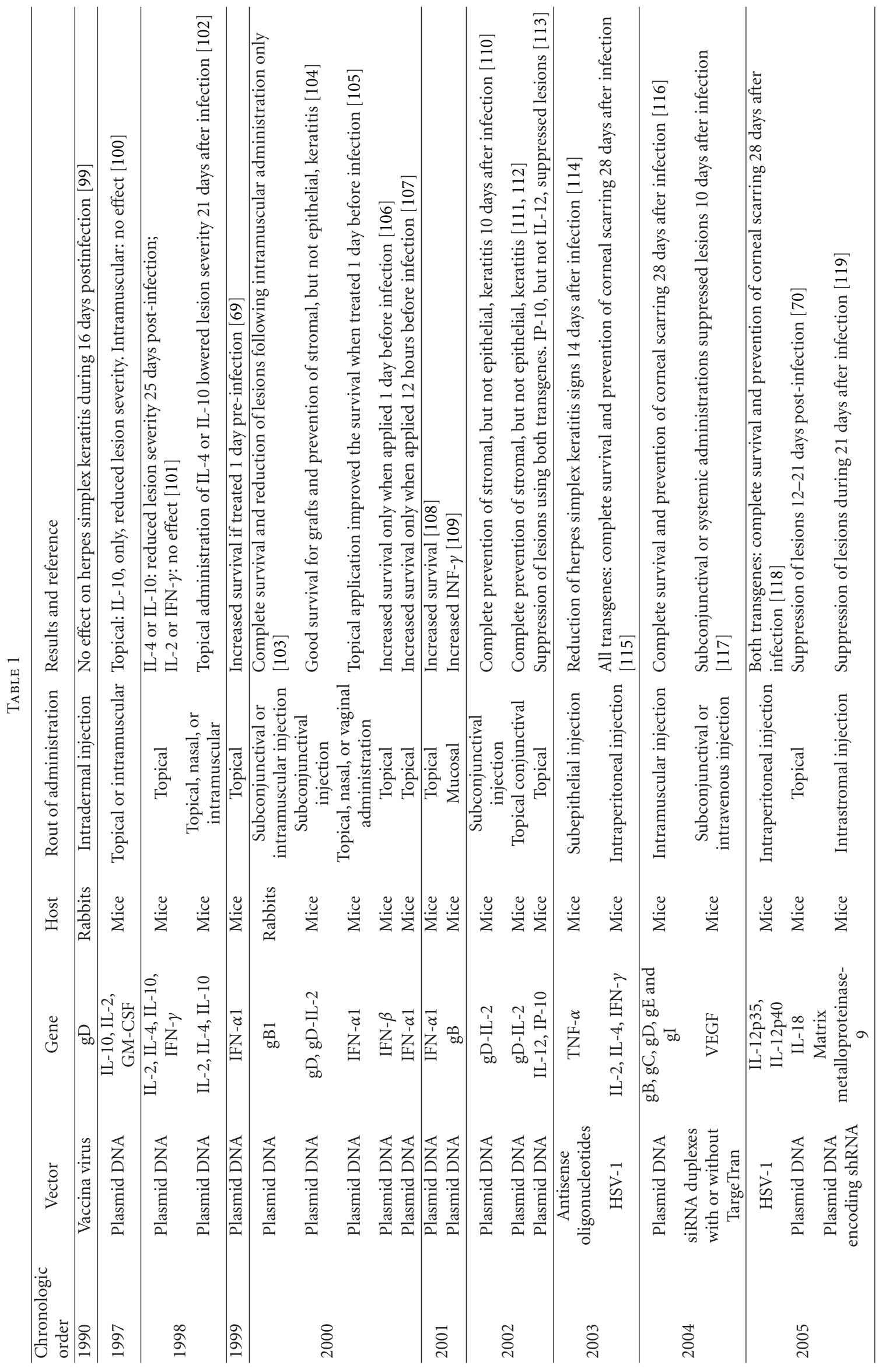




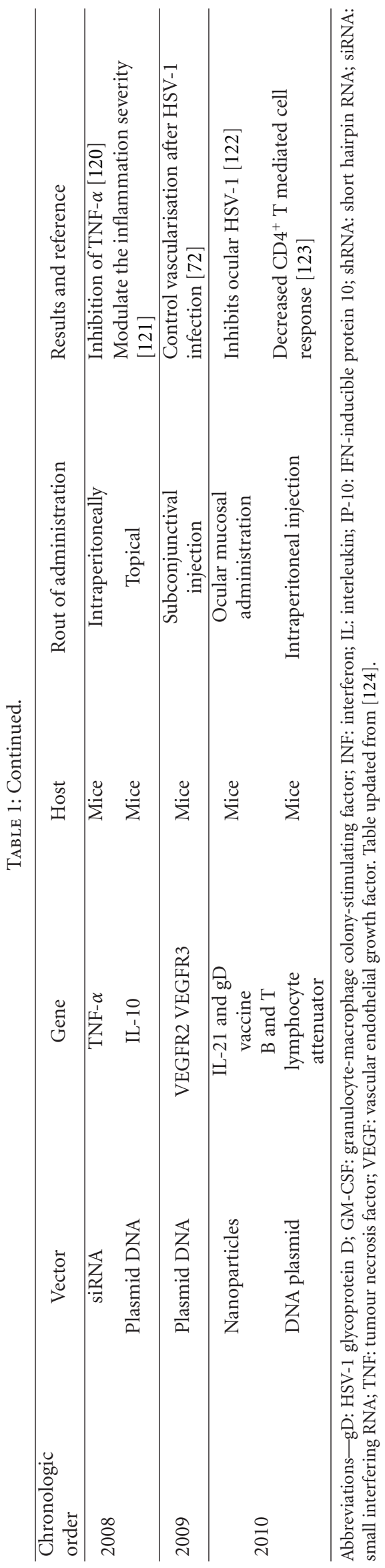


VEGFR1 and/or VEGFR2 reduces lesions and angiogenesis. Additionally, siRNA targeting glycoprotein E expression, which mediates cell-to-cell spread and immune evasion, was shown to suppress HSV-1 active infection in vitro [140]. Knock-down of glycoprotein D was also achieved using siRNA on HSV-1 infected human conjunctival epithelium in vitro [141]. Using in vitro plaque test, HSV-1 replication was also inhibited by siRNAs against the UL39 gene encoding the large subunit of ribonucleotide reductase, ICP6 [142]. Although siRNA based approaches are highly specific, they are yet still expensive, and not really reproducible due to variability in efficiency and transient expression nature of the technology.

Aptamers. Oligonucleotide sequences with the capacity to recognize specific target molecules with high affinity and specificity, referred to as "aptamers", are beginning to emerge as a class of molecules that compete with antibodies in both therapeutic and diagnostic applications. Recent studies have shown in vivo inhibition of rat corneal angiogenesis by targeting angiopoietin-1 with nuclease-resistant RNA aptamers [129].

Homing Endonucleases. Targeting endonucleases to HSV-1 genome for excising is an emerging new concept for antiviral gene therapy. Homing endonucleases are a group of restriction enzymes encoded by introns and inteins. Their recognition sites are rare, however, custom made endonucleases, namely meganucleases, can be made targeting specific viral sequences for gene therapy $[13,14,130,143,144]$. Anti-HSV custom-made meganucleases were recently shown to prevent the infection of cultured cells by wild-type HSV-1 [130].

4.3. Gene Therapy for New Targets. Several viral components have been proposed as promising targets for antiviral drug discovery by targeting them in a highly selective and effective manner [145]. The delivery of genes encoding agents that are capable of disrupting numerous biological processes is a key concept. Targeting the reverse transcriptase can block the transcription process [146]. Viral surface receptors also represents attractive targets [147], for example, CC chemokine receptor type 5 (CCR5) which is a major coreceptor important for efficient viral entry into cells. Additionally, a number of replication proteins serves as interesting targets for gene therapy, such as thymidine kinase UL23, ribonucleotide reductase UL39, 40, deoxyuridine diphosphatase UL50, uracil-DNA glycosylase (UL2), and alkaline nuclease (UL12) [148]. Other strategies include the inhibition of DNA polymerase by specific peptides or small molecules [149, 150], nuclear localisation signalling molecules [151], and the inhibition of protein-protein interactions [145], where a single substitutions in one subunit of a protein-protein interface can completely disrupt subunit interactions. For example, interruption of a few hydrogen bonds between subunits UL30 (Pol) and UL42 may represent an interesting target for new anti-HSV-1 drugs [149].

\section{Future Direction}

The potential in the treatment of many genetic diseases and viral infections is progressively elevating the attention and awareness towards this new era of highly specialized treatment. The fact that gene therapy is now being clinically evaluated, promotes the massive research that is conducted currently in animal models. It is well established that therapeutic genes or molecules can be transferred to the cornea by direct application of naked DNA, electric pulse, ballistic transfer with a gene gun, viral and non-viral vectors, or several creative combinations of these approaches. The choice of the appropriate vector for targeting HSV-1 is essential for successful gene therapy. The expression profile, bioavailability, biodegradability, and specificity of the vector are the main variables currently evaluated by several research groups to achieve the ideal combination. Successful gene therapy requires the choice of the right vector for each particular disease. Choices are made based on the ability of the targeted cells to uptake the vector, expression of the transgene in a cell-specific manner, and maintenance of expression for the period of time needed to tackle the disease. For chronic cases not requiring a surgery, local application to the cornea is usually preferred. However, pretreatment of corneas ex vivo in eye banks with specialised areas and trained staff is a new practical approach to corneal HSV-1 gene therapy. This can help decrease transplants rejection due to chronic herpetic keratitis and minimise the risk of in vivo gene therapy.

\section{References}

[1] S. Kaye and A. Choudhary, "Herpes simplex keratitis," Progress in Retinal and Eye Research, vol. 25, no. 4, pp. 355380, 2006.

[2] R. M. Shtein, D. D. Garcia, D. C. Musch, and V. M. Elner, "Herpes simplex virus keratitis. Histopathologic inflammation and corneal allograft rejection," Ophthalmology, vol. 116, no. 7, pp. 1301-1305, 2009.

[3] J. S. Smith and N. J. Robinson, "Age-specific prevalence of infection with herpes simplex virus types 2 and 1: a global review," Journal of Infectious Diseases, vol. 186, supplement 1, pp. S3-S28, 2002.

[4] D. Theil, T. Derfuss, I. Paripovic et al., "Latent herpesvirus infection in human trigeminal ganglia causes chronic immune response," The American Journal of Pathology, vol. 163, no. 6, pp. 2179-2184, 2003.

[5] A. B. Nesburn, M. L. Cook, and J. G. Stevens, "Latent herpes simplex virus. Isolation from rabbit trigeminal ganglia between episodes of recurrent ocular infection," Archives of Ophthalmology, vol. 88, no. 4, pp. 412-417, 1972.

[6] K. D. Croen, J. M. Ostrove, L. J. Dragovic, J. E. Smialek, and S. E. Straus, "Latent herpes simplex virus in human trigeminal ganglia," The New England Journal of Medicine, vol. 317, no. 23, pp. 1427-1432, 1987.

[7] Y. Furuta, T. Takasu, K. C. Sato, S. Fukuda, Y. Inuyama, and K. Nagashima, "Latent herpes simplex virus type 1 in human geniculate ganglia," Acta Neuropathologica, vol. 84, no. 1, pp. 39-44, 1992.

[8] C. Shimeld, A. B. Tullo, D. L. Easty, and J. Thomsitt, "Isolation of herpes simplex virus from the cornea in chronic 
stromal keratitis," British Journal of Ophthalmology, vol. 66, no. 10, pp. 643-647, 1982.

[9] D. P. Kennedy, C. Clement, R. L. Arceneaux, P. S. Bhattacharjee, T. S. Huq, and J. M. Hill, "Ocular herpes simplex virus type 1: is the cornea a reservoir for viral latency or a fast pit stop?" Cornea, vol. 30, no. 3, pp. 251-259, 2011.

[10] A. V. Farooq and D. Shukla, "Corneal latency and transmission of herpes simplex virus-1," Future Virology, vol. 6, no. 1, pp. 101-108, 2011.

[11] P. A. Thomas and P. Geraldine, "Infectious keratitis," Current Opinion in Infectious Diseases, vol. 20, no. 2, pp. 129-141, 2007.

[12] M. L. Edelstein, M. R. Abedi, and J. Wixon, "Gene therapy clinical trials worldwide to 2007- an update," Journal of Gene Medicine, vol. 9, no. 10, pp. 833-842, 2007.

[13] R. Galetto, P. Duchateau, and F. Pâques, "Targeted approaches for gene therapy and the emergence of engineered meganucleases," Expert Opinion on Biological Ther$a p y$, vol. 9, no. 10, pp. 1289-1303, 2009.

[14] S. Arnould, C. Delenda, S. Grizot et al., "The I-CreI meganuclease and its engineered derivatives: applications from cell modification to gene therapy," Protein Engineering, Design and Selection, vol. 24, no. 1-2, pp. 27-31, 2011.

[15] Z. Hong Zhou, D. H. Chen, J. Jakana, F. J. Rixon, and W. Chiu, "Visualization of tegument-capsid interactions and DNA in intact herpes simplex virus type 1 virions," Journal of Virology, vol. 73, no. 4, pp. 3210-3218, 1999.

[16] K. Grünewald, P. Desai, D. C. Winkler et al., "Threedimensional structure of herpes simplex virus from cryoelectron tomography," Science, vol. 302, no. 5649, pp. 13961398, 2003.

[17] J. E. Knickelbein, K. M. Khanna, M. B. Yee, C. J. Baty, P. R. Kinchington, and R. L. Hendricks, "Noncytotoxic lytic granule-mediated $\mathrm{CD}^{8+} \mathrm{T}$ cell inhibition of HSV-1 reactivation from neuronal latency," Science, vol. 322, no. 5899, pp. 268-271, 2008.

[18] H. Ghiasi, S. Cai, G. C. Perng, A. B. Nesburn, and S. L. Wechsler, "Both $\mathrm{CD}^{4+}$ and $\mathrm{CD}^{8+} \mathrm{T}$ cells are involved in protection against HSV-1 induced corneal scarring," British Journal of Ophthalmology, vol. 84, no. 4, pp. 408-412, 2000.

[19] E. M. Elnifro, A. M. Ashshi, R. J. Cooper, and P. E. Klapper, "Multiplex PCR: optimization and application in diagnostic virology," Clinical Microbiology Reviews, vol. 13, no. 4, pp. 559-570, 2000.

[20] A. M. A. El-Aal, M. El Sayed, E. Mohammed, M. Ahmed, and M. Fathy, "Evaluation of herpes simplex detection in corneal scrapings by three molecular methods," Current Microbiology, vol. 52, no. 5, pp. 379-382, 2006.

[21] P. Y. Robert, A. Liekfeld, S. Metzner et al., "Specific antibody production in herpes keratitis: intraocular inflammation and corneal neovascularisation as predicting factors," Graefe's Archive for Clinical and Experimental Ophthalmology, vol. 244, no. 2, pp. 210-215, 2006.

[22] G. Satpathy, A. K. Mishra, R. Tandon et al., "Evaluation of tear samples for Herpes Simplex Virus 1 (HSV) detection in suspected cases of viral keratitis using PCR assay and conventional laboratory diagnostic tools," British Journal of Ophthalmology, vol. 95, no. 3, pp. 415-418, 2011.

[23] H. E. Kaufman, E. D. Varnell, and H. W. Thompson, "Trifluridine, cidofovir, and penciclovir in the treatment of experimental herpetic keratitis," Archives of Ophthalmology, vol. 116, no. 6, pp. 777-780, 1998.

[24] N. Castela, N. Vermerie, F. Chast et al., "Ganciclovir ophthalmic gel in herpes simplex virus rabbit keratitis: intraocular penetration and efficacy," Journal of Ocular Pharmacology, vol. 10, no. 2, pp. 439-451, 1994.

[25] J. J. Sanitato, P. A. Asbell, and E. D. Varnell, "Acyclovir in the treatment of herpetic stromal disease," American Journal of Ophthalmology, vol. 98, no. 5, pp. 537-547, 1984.

[26] E. Miserocchi, G. Modorati, L. Galli, and P. Rama, "Efficacy of valacyclovir vs acyclovir for the prevention of recurrent herpes simplex virus eye disease: a Pilot Study," American Journal of Ophthalmology, vol. 144, no. 4, pp. 547.e1-551.e1, 2007.

[27] E. Sozen, A. M. Avunduk, and N. Akyol, "Comparison of efficacy of oral valacyclovir and topical acyclovir in the treatment of herpes simplex keratitis: a randomized clinical trial," Chemotherapy, vol. 52, no. 1, pp. 29-31, 2005.

[28] T. J. Liesegang, "Herpes simplex virus epidemiology and ocular importance," Cornea, vol. 20, no. 1, pp. 1-13, 2001.

[29] B. A. Barron, L. Gee, W. W. Hauck et al., "Herpetic eye disease study: a controlled trial of oral acyclovir for herpes simplex stromal keratitis," Ophthalmology, vol. 101, no. 12, pp. 18711882, 1994.

[30] M. van Velzen, B. Freek van Loenen, J. W. Roland Meesters et al., "Latent acyclovir resistant herpes simplex type 1 in trigeminal ganglia of immunecompetent individuals," Journal of Infectious Diseases. In press.

[31] K. Choong, N. J. Walker, A. J. Apel, and M. Whitby, "Aciclovir-resistant herpes keratitis," Clinical and Experimental Ophthalmology, vol. 38, no. 3, pp. 309-313, 2010.

[32] R. Duan, R. D. De Vries, A. D. M. E. Osterhaus, L. Remeijer, and G. M. G. M. Verjans, "Acyclovir-resistant corneal HSV1 isolates from patients with herpetic keratitis," Journal of Infectious Diseases, vol. 198, no. 5, pp. 659-663, 2008.

[33] K. F. Tabbara and N. Al Balushi, "Topical ganciclovir in the treatment of acute herpetic keratitis," Clinical Ophthalmology, vol. 4, no. 1, pp. 905-912, 2010.

[34] J. S. Pepose, T. L. Keadle, and L. A. Morrison, "Ocular herpes simplex: changing epidemiology, emerging disease patterns, and the potential of vaccine prevention and therapy," American Journal of Ophthalmology, vol. 141, no. 3, pp. 547.e2557.e2, 2006.

[35] D. M. Koelle and H. Ghiasi, "Prospects for developing an effective vaccine against ocular herpes simplex virus infection," Current Eye Research, vol. 30, no. 11, pp. 929-942, 2005.

[36] T. Borrás, "Recent developments in ocular gene therapy," Experimental Eye Research, vol. 76, no. 6, pp. 643-652, 2003.

[37] P. D. Bieniasz, "Intrinsic immunity: a front-line defense against viral attack," Nature Immunology, vol. 5, no. 11, pp. 1109-1115, 2004.

[38] N. Yan and Z. J. Chen, "Intrinsic antiviral immunity," Nature Immunology, vol. 13, no. 3, pp. 214-222, 2012.

[39] R. R. Mohan, J. C. Tovey, A. Sharma, and A. Tandon, "Gene therapy in the Cornea: 2005 to present," Progress in Retinal and Eye Research, vol. 31, no. 1, pp. 43-64, 2012.

[40] H. B. Oral, D. F. P. Larkin, Z. Fehervari et al., "Ex vivo adenovirus-mediated gene transfer and immunomodulatory protein production in human cornea," Gene Therapy, vol. 4, no. 7, pp. 639-647, 1997.

[41] N. K. Green, C. W. Herbert, S. J. Hale et al., "Extended plasma circulation time and decreased toxicity of polymer-coated adenovirus," Gene Therapy, vol. 11, no. 16, pp. 1256-1263, 2004.

[42] M. Stevenson, A. B. H. Hale, S. J. Hale et al., "Incorporation of a laminin-derived peptide (SIKVAV) on polymermodified adenovirus permits tumor-specific targeting via 
a6-integrins," Cancer Gene Therapy, vol. 14, no. 4, pp. 335345, 2007.

[43] M. R. Duffy, A. L. Parker, A. C. Bradshaw et al., "Manipulation of adenovirus interactions with host factors for gene therapy applications," Nanomedicine, vol. 7, no. 2, pp. 271288, 2012.

[44] A. Recchia, L. Perani, D. Sartori, C. Olgiati, and F. Mavilio, "Site-specific integration of functional transgenes into the human genome by adeno/AAV hybrid vectors," Molecular Therapy, vol. 10, no. 4, pp. 660-670, 2004.

[45] A. Recchia, R. J. Parks, S. Lamartina et al., "Site-specific integration mediated by a hybrid adenovirus/adenoassociated virus vector," Proceedings of the National Academy of Sciences of the United States of America, vol. 96, no. 6, pp. 2615-2620, 1999.

[46] D. L. Glauser, M. Ackermann, O. Saydam, and C. Fraefel, "Chimeric herpes simplex virus/adeno-associated virus amplicon vectors," Current Gene Therapy, vol. 6, no. 3, pp. 315-324, 2006.

[47] J. W. B. Bainbridge, A. Mistry, F. C. Schlichtenbrede et al., "Stable rAAV-mediated transduction of rod and cone photoreceptors in the canine retina," Gene Therapy, vol. 10, no. 16, pp. 1336-1344, 2003.

[48] T. Hudde, S. A. Rayner, M. De Alwis et al., "Adeno-associated and herpes simplex viruses as vectors for gene transfer to the corneal endothelium," Cornea, vol. 19, no. 3, pp. 369-373, 2000.

[49] L. J. Lai, K. K. Lin, G. N. Foulks, L. Ma, X. Xiao, and K. H. Chen, "Highly efficient ex vivo gene delivery into human corneal endothelial cells by recombinant adeno-associated virus," Current Eye Research, vol. 30, no. 3, pp. 213-219, 2005.

[50] A. C. Nathwani, J. T. Gray, J. McIntosh et al., "Safe and efficient transduction of the liver after peripheral vein infusion of self-complementary AAV vector results in stable therapeutic expression of human FIX in nonhuman primates," Blood, vol. 109, no. 4, pp. 1414-1421, 2007.

[51] M. L. Hirsch, L. Green, M. H. Porteus, and R. J. Samulski, "Self-complementary AAV mediates gene targeting and enhances endonuclease delivery for double-strand break repair," Gene Therapy, vol. 17, no. 9, pp. 1175-1180, 2010.

[52] C. N. Mattar, N. M. Dighe, S. N. Waddington et al., "Long-term transgene expression in new-born Cynomolgus Macaques following intra-uterine gene transfer of selfcomplementary AAV," in Molecular Therapy, Nature Publishing Group, 2011.

[53] Q. Xu, B. Chou, B. Fitzsimmons et al., "In vivo gene knockdown in rat dorsal root ganglia mediated by selfcomplementary adeno-associated virus serotype 5 following intrathecal delivery," PLoS ONE, vol. 7, no. 3, Article ID e32581, 2012.

[54] V. W. Choi, D. M. McCarty, and R. J. Samulski, "AAV hybrid serotypes: improved vectors for gene delivery," Current Gene Therapy, vol. 5, no. 3, pp. 299-310, 2005.

[55] A. Asokan, D. V. Schaffer, and R. J. Samulski, "The AAV vector toolkit: poised at the clinical crossroads," Molecular Therapy, vol. 20, no. 4, pp. 699-708, 2012.

[56] Z. Wu, A. Asokan, and R. J. Samulski, "Adeno-associated virus serotypes: vector toolkit for human gene therapy," Molecular Therapy, vol. 14, no. 3, pp. 316-327, 2006.

[57] C. Hippert, S. Ibanes, N. Serratrice et al., "Corneal transduction by intra-stromal injection of AAV vectors in vivo in the mouse and ex vivo in human explants," PLoS ONE, vol. 7, no. 4, Article ID e35318, 2012.
[58] L. H. Suh, C. Zhang, R. S. Chuck et al., "Cryopreservation and lentiviral-mediated genetic modification of human primary cultured corneal endothelial cells," Investigative Ophthalmology and Visual Science, vol. 48, no. 7, pp. 30563061, 2007.

[59] S. Mulik, S. Sharma, A. Suryawanshi et al., "Activation of endothelial roundabout receptor 4 reduces the severity of virus-induced keratitis," The Journal of Immunology, vol. 186, no. 12, pp. 7195-7204, 2011.

[60] M. Nosov, M. Wilk, M. Morcos et al., "Role of lentivirus mediated overexpression of programmed death ligand 1 on corneal allograft survival," American Journal of Transplantation, vol. 12, no. 5, pp. 1313-1322, 2012.

[61] A. P. Bemelmans, Y. Arsenijevic, and F. Majo, "Efficient lentiviral gene transfer into corneal stroma cells using a femtosecond laser," Gene Therapy, vol. 16, no. 7, pp. 933-938, 2009.

[62] J. J. Bradshaw, W. F. Obritsch, B. J. Cho, D. S. Gregerson, and E. J. Holland, "Ex vivo transduction of corneal epithelial progenitor cells using a retroviral vector," Investigative Ophthalmology and Visual Science, vol. 40, no. 1, pp. 230-235, 1999.

[63] A. Behrens, E. M. Gordon, L. Li et al., "Retroviral gene therapy vectors for prevention of excimer laser-induced corneal haze," Investigative Ophthalmology and Visual Science, vol. 43, no. 4, pp. 968-977, 2002.

[64] M. I. Rosenblatt and D. T. Azar, "Gene therapy of the corneal epithelium," International Ophthalmology Clinics, vol. 44, no. 3, pp. 81-90, 2004.

[65] H. Peng, R. B. Hamanaka, J. Katsnelson et al., "MicroRNA31 targets FIH-1 to positively regulate corneal epithelial glycogenmetabolism," The FASEB Journal. In press.

[66] M. A. Kay, J. C. Glorioso, and L. Naldini, "Viral vectors for gene therapy: the art of turning infectious agents into vehicles of therapeutics," Nature Medicine, vol. 7, no. 1, pp. 33-40, 2001.

[67] J. R. Piccotti, S. Y. Chan, A. M. VanBuskirk, E. J. Eichwald, and D. K. Bishop, "Are Th2 helper T lymphocytes beneficial, deleterious, or irrelevant in promoting allograft survival?" Transplantation, vol. 63, no. 5, pp. 619-624, 1997.

[68] S. U. Stechschulte, A. M. Joussen, H. A. Von Recum et al., "Rapid ocular angiogenic control via naked DNA delivery to cornea," Investigative Ophthalmology and Visual Science, vol. 42, no. 9, pp. 1975-1979, 2001.

[69] S. Noisakran, I. L. Campbell, and D. J. J. Carr, "Ectopic expression of DNA encoding IFN- $\alpha 1$ in the cornea protects mice from herpes simplex virus type 1-induced encephalitis," The Journal of Immunology, vol. 162, no. 7, pp. 4184-4190, 1999.

[70] B. Kim, S. Lee, S. Suvas, and B. T. Rouse, "Application of plasmid DNA encoding IL-18 diminishes development of herpetic stromal keratitis by antiangiogenic effects," The Journal of Immunology, vol. 175, no. 1, pp. 509-516, 2005.

[71] P. D. Jani, N. Singh, C. Jenkins et al., "Nanoparticles sustain expression of Flt intraceptors in the cornea and inhibit injury-induced corneal angiogenesis," Investigative Ophthalmology and Visual Science, vol. 48, no. 5, pp. 20302036, 2007.

[72] T. R. Wuest and D. J. J. Carr, "VEGF-A expression by HSV-1infected cells drives corneal lymphangiogenesis," The Journal of Experimental Medicine, vol. 207, no. 1, pp. 101-115, 2010.

[73] L. J. Lai, X. Xiao, and J. H. Wu, "Inhibition of corneal neovascularization with endostatin delivered by adeno-associated 
viral (AAV) vector in a mouse corneal injury model," Journal of Biomedical Science, vol. 14, no. 3, pp. 313-322, 2007.

[74] Y. Qazi, B. Stagg, N. Singh et al., "Nanoparticle-mediated delivery of shRNA. VEGF-A plasmids regresses corneal neovascularization," Investigative Ophthalmology \& Visual Science, vol. 53, no. 6, pp. 2837-2844, 2012.

[75] Z. R. Li, L. Yao, J. Li et al., "Celastrol nanoparticles inhibit corneal neovascularization induced by suturing in rats," International Journal of Nanomedicine, vol. 7, pp. 1163-1173, 2012.

[76] B. Bareiss, M. Ghorbani, F. Li et al., "Controlled release of acyclovir through bioengineered corneal implants with silica nanoparticle carriers. Open tissue engineering and regenerative," Medicine Journal, vol. 3, pp. 10-17, 2010.

[77] M. Garcia-Fuentes and M. J. Alonso, "Chitosan-based drug nanocarriers: where do we stand?" Journal of Controlled Release, vol. 161, no. 2, pp. 496-504, 2012.

[78] T. Nishi, K. Yoshizato, S. Yamashiro et al., "High-efficiency in vivo gene transfer using intraarterial plasmid DNA injection following in vivo electroporation," Cancer Research, vol. 56, no. 5, pp. 1050-1055, 1996.

[79] J. J. Drabick, J. Glasspool-Malone, S. Somiari, A. King, and R. W. Malone, "Cutaneous transfection and immune responses to intradermal nucleic acid vaccination are significantly enhanced by in vivo electropermeabilization," Molecular Therapy, vol. 3, no. 2, pp. 249-255, 2001.

[80] S. Sonoda, K. Tachibana, E. Uchino et al., "Gene transfer to corneal epithelium and keratocytes mediated by ultrasound with microbubbles," Investigative Ophthalmology and Visual Science, vol. 47, no. 2, pp. 558-564, 2006.

[81] V. Zderic, J. I. Clark, R. W. Martin, and S. Vaezy, "Ultrasound-enhanced transcorneal drug delivery," Cornea, vol. 23, no. 8, pp. 804-811, 2004.

[82] T. Yamashita, S. Sonoda, R. Suzuki et al., "A novel bubble liposome and ultrasound-mediated gene transfer to ocular surface: RC-1 cells in vitro and conjunctiva in vivo," Experimental Eye Research, vol. 85, no. 6, pp. 741-748, 2007.

[83] H. L. Li, X. Z. Zheng, H. P. Wang, F. Li, Y. Wu, and L. F. Du, "Ultrasound-targeted microbubble destruction enhances AAV-mediated gene transfection in human RPE cells in vitro and rat retina in vivo," Gene Therapy, vol. 16, no. 9, pp. 1146-1153, 2009.

[84] D. J. Wells, "Electroporation and ultrasound enhanced nonviral gene delivery in vitro and in vivo," Cell Biology and Toxicology, vol. 26, no. 1, pp. 21-28, 2010.

[85] R. Zhou and D. A. Dean, "Gene transfer of interleukin 10 to the murine cornea using electroporation," Experimental Biology and Medicine, vol. 232, no. 3, pp. 362-369, 2007.

[86] Y. Oshima, T. Sakamoto, I. Yamanaka, T. Nishi, T. Ishibashi, and H. Inomata, "Targeted gene transfer to corneal endothelium in vivo by electric pulse," Gene Therapy, vol. 5, no. 10, pp. 1347-1354, 1998.

[87] Y. Oshima, T. Sakamoto, T. Hisatomi et al., "Targeted gene transfer to corneal stroma in vivo by electric pulses," Experimental Eye Research, vol. 74, no. 2, pp. 191-198, 2002.

[88] E. Zeira, A. Manevitch, A. Khatchatouriants et al., "Femtosecond infrared laser-An efficient and safe in vivo gene delivery system for prolonged expression," Molecular Ther$a p y$, vol. 8, no. 2, pp. 342-350, 2003.

[89] M. Sawa, K. Awazu, T. Takahashi et al., "Application of femtosecond ultrashort ulse laser to photodynamic therapy mediated by indocyanine green," British Journal of Ophthalmology, vol. 88, no. 6, pp. 826-831, 2004.
[90] P. H. Tan, M. Manunta, N. Ardjomand et al., "Antibody targeted gene transfer to endothelium," Journal of Gene Medicine, vol. 5, no. 4, pp. 311-323, 2003.

[91] R. G. Pillai, S. C. Beutelspacher, D. F. P. Larkin, and A. J. T. George, "Expression of the chemokine antagonist vMIP II using a non-viral vector can prolong corneal allograft survival," Transplantation, vol. 85, no. 11, pp. 1640-1647, 2008.

[92] L. Collins and J. W. Fabre, "A synthetic peptide vector system for optimal gene delivery to corneal endothelium," Journal of Gene Medicine, vol. 6, no. 2, pp. 185-194, 2004.

[93] D. L. Tanelian, M. A. Barry, S. A. Johnston, T. Le, and G. Smith, "Controlled gene gun delivery and expression of DNA within the cornea," BioTechniques, vol. 23, no. 3, pp. 484-488, 1997.

[94] S. Klebe, P. J. Sykes, D. J. Coster, D. C. Bloom, and K. A. Williams, "Gene transfer to ovine corneal endothelium," Clinical and Experimental Ophthalmology, vol. 29, no. 5, pp. 316-322, 2001.

[95] T. Hudde, S. A. Rayner, R. M. Comer et al., "Activated polyamidoamine dendrimers, a non-viral vector for gene transfer to the corneal endothelium," Gene Therapy, vol. 6, no. 5, pp. 939-943, 1999.

[96] U. Pleyer, D. Groth, B. Hinz et al., "Efficiency and toxicity of liposome-mediated gene transfer to corneal endothelial cells," Experimental Eye Research, vol. 73, no. 1, pp. 1-7, 2001.

[97] J. S. Pepose et al., "Herpes simplex virus diseases: anterior segment of the eye," Ocular Infection and Immunity, pp. 905932, 1996.

[98] L. Remeijer, A. D. M. E. Osterhaus, and G. M. G. M. Verjans, "Human herpes simplex virus keratitis: the pathogenesis revisited," Ocular Immunology and Inflammation, vol. 12, no. 4, pp. 255-285, 2004.

[99] A. B. Nesburn, H. Ghiasi, and L. Wechsler, "Ocular safety and efficacy of an HSV-1 gD vaccine during primary and latent infection," Investigative Ophthalmology and Visual Science, vol. 31, no. 8, pp. 1497-1502, 1990.

[100] M. Daheshia, N. Kuklin, S. Kanangat, E. Manickan, and B. T. Rouse, "Suppression of ongoing ocular inflammatory disease by topical administration of plasmid DNA encoding IL-10," The Journal of Immunology, vol. 159, no. 4, pp. 1945-1952, 1997.

[101] S. Chun, M. Daheshia, N. A. Kuklin, and B. T. Rouse, "Modulation of viral immunoinflammatory responses with cytokine DNA administered by different routes," Journal of Virology, vol. 72, no. 7, pp. 5545-5551, 1998.

[102] M. Daheshia, N. Kuklin, E. Manickan, S. Chun, and B. T. Rouse, "Immune induction and modulation by topical ocular administration of plasmid DNA encoding antigens and cytokines," Vaccine, vol. 16, no. 11-12, pp. 1103-1110, 1998.

[103] E. Caselli, P. G. Balboni, C. Incorvaia et al., "Local and systemic inoculation of DNA or protein gB1s-based vaccines induce a protective immunity against rabbit ocular HSV-1 infection," Vaccine, vol. 19, no. 9-10, pp. 1225-1231, 2000.

[104] T. Inoue, Y. Inoue, T. Nakamura et al., "Preventive effect of local plasmid DNA vaccine encoding gD or gD-IL-2 on herpetic keratitis," Investigative Ophthalmology and Visual Science, vol. 41, no. 13, pp. 4209-4215, 2000.

[105] S. Noisakran and D. J. J. Carr, "Plasmid DNA encoding IFN$\alpha 1$ antagonizes herpes simplex virus type I ocular infection through $\mathrm{CD}^{4+}$ and $\mathrm{CD}^{8+} \mathrm{T}$ lymphocytes," The Journal of Immunology, vol. 164, no. 12, pp. 6435-6443, 2000. 
[106] B. Cui and D. J. J. Carr, "A plasmid construct encoding murine interferon beta antagonizes the replication of herpes simplex virus type I in vitro and in vivo," Journal of Neuroimmunology, vol. 108, no. 1-2, pp. 92-102, 2000.

[107] S. Noisakran and D. J. J. Carr, "Therapeutic efficacy of DNA encoding IFN- $\alpha 1$ against corneal HSV-1 infection," Current Eye Research, vol. 20, no. 5, pp. 405-412, 2000.

[108] S. Noisakran and D. J. J. Carr, "Topical application of the cornea post-infection with plasmid DNA encoding interferon- $\alpha 1$ but not recombinant interferon- $\alpha$ A reduces herpes simplex virus type 1-induced mortality in mice," Journal of Neuroimmunology, vol. 121, no. 1-2, pp. 49-58, 2001.

[109] S. K. Eo, S. Lee, S. Chun, and B. T. Rouse, "Modulation of immunity against herpes simplex virus infection via mucosal genetic transfer of plasmid DNA encoding chemokines," Journal of Virology, vol. 75, no. 2, pp. 569-578, 2001.

[110] T. Inoue, Y. Inoue, T. Nakamura et al., "The effect of immunization with herpes simplex virus glycoprotein D fused with interleukin-2 against murine herpetic keratitis," Japanese Journal of Ophthalmology, vol. 46, no. 4, pp. 370376, 2002.

[111] T. Inoue, Y. Inoue, K. Hayashi et al., "Topical administration of HSV gD-IL-2 DNA is highly protective against murine herpetic stromal keratitis," Cornea, vol. 21, no. 1, pp. 106110, 2002.

[112] T. Inoue, Y. Inoue, K. Hayashi et al., "Effect of herpes simplex virus-1 gD or gD-IL-2 DNA vaccine on herpetic keratitis," Cornea, vol. 21, no. 7, pp. S79-S85, 2002.

[113] S. Lee, M. Zheng, S. Deshpande, S. K. Eo, T. A. Hamilton, and B. T. Rouse, "IL-12 suppresses the expression of ocular immunoinflammatory lesions by effects on angiogenesis," Journal of Leukocyte Biology, vol. 71, no. 3, pp. 469-476, 2002.

[114] S. Wasmuth, D. Bauer, Y. Yang, K. P. Steuhl, and A. Heiligenhaus, "Topical treatment with antisense oligonucleotides targeting tumor necrosis factor- $\alpha$ in herpetic stromal keratitis," Investigative Ophthalmology and Visual Science, vol. 44, no. 12 , pp. 5228-5234, 2003.

[115] Y. Osorio and H. Ghiasi, "Comparison of adjuvant efficacy of herpes simplex virus type 1 recombinant viruses expressing TH1 and TH2 cytokine genes," Journal of Virology, vol. 77, no. 10, pp. 5774-5783, 2003.

[116] Y. Osorio, J. Cohen, and H. Ghiasi, "Improved protection from primary ocular HSV-1 infection and establishment of latency using multigenic DNA vaccines," Investigative Ophthalmology and Visual Science, vol. 45, no. 2, pp. 506-514, 2004.

[117] B. Kim, Q. Tang, P. S. Biswas et al., "Inhibition of ocular angiogenesis by siRNA targeting vascular endothelial growth factor pathway genes: therapeutic strategy for herpetic stromal keratitis," The American Journal of Pathology, vol. 165, no. 6, pp. 2177-2185, 2004.

[118] Y. Osorio and H. Ghiasi, "Recombinant herpes simplex virus type 1 (HSV-1) codelivering interleukin-12p35 as a molecular adjuvant enhances the protective immune response against ocular HSV-1 challenge," Journal of Virology, vol. 79, no. 6, pp. 3297-3308, 2005.

[119] A. K. Azkur, B. Kim, S. Suvas, Y. Lee, U. Kumaraguru, and B. T. Rouse, "Blocking mouse MMP-9 production in tumor cells and mouse cornea by short hairpin (sh) RNA encoding plasmids," Oligonucleotides, vol. 15, no. 2, pp. 72-84, 2005.

[120] B. Choi, Y. Hwang, H. J. Kwon et al., "Tumor necrosis factor alpha small interfering RNA decreases herpes simplex virus-induced inflammation in a mouse model," Journal of Dermatological Science, vol. 52, no. 2, pp. 87-97, 2008.

[121] P. P. Sarangi, S. Sehrawat, S. Suvas, and B. T. Rouse, "IL10 and natural regulatory $\mathrm{T}$ cells: two independent antiinflammatory mechanisms in herpes simplex virus-induced ocular immunopathology," The Journal of Immunology, vol. 180, no. 9, pp. 6297-6306, 2008.

[122] K. Hu, J. Dou, F. Yu et al., "An ocular mucosal administration of nanoparticles containing DNA vaccine pRSC-gD-IL-21 confers protection against mucosal challenge with herpes simplex virus type 1 in mice," Vaccine, vol. 29, no. 7, pp. 1455-1462, 2011.

[123] L. Xia, S. Zhang, J. Zhou, and Y. Li, "A crucial role for B and $\mathrm{T}$ lymphocyte attenuator in preventing the development of $\mathrm{CD}^{4+} \mathrm{T}$ cell-mediated herpetic stromal keratitis," Molecular Vision, vol. 16, pp. 2071-2083, 2010.

[124] E. A. Klausner, D. Peer, R. L. Chapman, R. F. Multack, and S. V. Andurkar, "Corneal gene therapy," Journal of Controlled Release, vol. 124, no. 3, pp. 107-133, 2007.

[125] A. Sancar, L. A. Lindsey-Boltz, K. Ünsal-Kaçmaz, and S. Linn, "Molecular mechanisms of mammalian DNA repair and the DNA damage checkpoints," Annual Review of Biochemistry, vol. 73, pp. 39-85, 2004.

[126] J. Liu, G. M. Schultz, S. S. Tuli et al., "Gene therapy of herpes simplex keratitis using hammerhead ribozymes," Investigative Ophtalmology and Visual Science, vol. 45, no. 5, abstract 1636, 2004.

[127] A. Peyman, M. Helsberg, G. Kretzschmar, M. Mag, S. Grabley, and E. Uhlmann, "Inhibition of viral growth by antisense oligonucleotides directed against the IE110 and the UL30 mRNA of herpes simplex virus type-1," Biological Chemistry Hoppe-Seyler, vol. 376, no. 3, pp. 195-198, 1995.

[128] M. Moerdyk-Schauwecker, D. A. Stein, K. Eide et al., "Inhibition of HSV-1 ocular infection with morpholino oligomers targeting ICP0 and ICP27," Antiviral Research, vol. 84, no. 2, pp. 131-141, 2009.

[129] R. R. White, S. Shan, C. P. Rusconi et al., "Inhibition of rat corneal angiogenesis by a nuclease-resistant RNA aptamer specific for angiopoietin-2," Proceedings of the National Academy of Sciences of the United States of America, vol. 100, no. 9, pp. 5028-5033, 2003.

[130] S. Grosse, N. Huot, C. Mahiet et al., "Meganuclease-mediated inhibition of HSV1 infection in cultured cells," Molecular Therapy, vol. 19, no. 4, pp. 694-702, 2011.

[131] N. Sarver, E. M. Cantin, P. S. Chang et al., "Ribozymes as potential anti-HIV-1 therapeutic agents," Science, vol. 247, no. 4947, pp. 1222-1225, 1990.

[132] S. Lainé, R. J. Scarborough, D. Lévesque et al., "In vitro and in vivo cleavage of HIV-1 RNA by new SOFA-HDV ribozymes and their potential to inhibit viral replication," RNA Biology, vol. 8, no. 2, 2011.

[133] P. Trang, A. Kilani, J. Kim, and F. Liu, "A ribozyme derived from the catalytic subunit of RNase P from Escherichia coli is highly effective in inhibiting replication of herpes simplex virus 1," Journal of Molecular Biology, vol. 301, no. 4, pp. 817826, 2000.

[134] S. T. Crooke, "Molecular mechanisms of action of antisense drugs," Biochimica et Biophysica Acta, vol. 1489, no. 1, pp. 3143, 1999.

[135] R. S. Grajewski, J. Li, S. Wasmuth et al., "Intravitreal treatment with antisense oligonucleotides targeting tumor necrosis factor-alpha in murine herpes simplex virus type 1 retinitis," Graefe's Archive for Clinical and Experimental Ophthalmology, vol. 250, no. 2, pp. 231-238, 2012. 
[136] P. L. Iversen, "Phosphorodiamidate morpholino oligomers: favorable properties for sequence-specific gene inactivation," Current Opinion in Molecular Therapeutics, vol. 3, no. 3, pp. 235-238, 2001.

[137] T. Li, Y. Zhang, L. Fu et al., "siRNA targeting the Leader sequence of SARS-CoV inhibits virus replication," Gene Therapy, vol. 12, no. 9, pp. 751-761, 2005.

[138] R. J. Sugrue, "Interactions between respiratory syncytial virus and the host cell: opportunities for antivirus strategies?" Expert Reviews in Molecular Medicine, vol. 8, no. 21, pp. 117, 2006.

[139] E. K. W. Hui, E. M. Yap, D. S. An, I. S. Y. Chen, and D. P. Nayak, "Inhibition of influenza virus matrix (M1) protein expression and virus replication by U6 promoter-driven and lentivirus-mediated delivery of siRNA," Journal of General Virology, vol. 85, no. 7, pp. 1877-1884, 2004.

[140] P. K. Bhuyan, K. Karikò, J. Capodici et al., "Short interfering RNA-mediated inhibition of herpes simplex virus type 1 gene expression and function during infection of human keratinocytes," Journal of Virology, vol. 78, no. 19, pp. 1027610281, 2004

[141] J. Akhtar, V. Tiwari, M. J. Oh et al., "HVEM and nectin-1 are the major mediators of herpes simplex virus 1 (HSV1) entry into human conjunctival epithelium," Investigative Ophthalmology and Visual Science, vol. 49, no. 9, pp. 40264035, 2008.

[142] R. Zhe, Z. Mei-Ying, K. Kitazato et al., "Effect of siRNA on HSV-1 plaque formation and relative expression levels of UL39 mRNA," Archives of Virology, vol. 153, no. 7, pp. 14011406, 2008.

[143] I. G. Muñoz, J. Prieto, S. Subramanian et al., "Molecular basis of engineered meganuclease targeting of the endogenous human RAG1 locus," Nucleic Acids Research, vol. 39, no. 2, pp. 729-743, 2011.

[144] A. Izmiryan, S. Basmaciogullari, A. Henry et al., "Efficient gene targeting mediated by a lentiviral vector-associated meganuclease," Nucleic Acids Research, vol. 39, no. 17, pp. 7610-7619, 2011.

[145] A. Loregian, H. S. Marsden, and G. Palù, "Protein-protein interactions as targets for antiviral chemotherapy," Reviews in Medical Virology, vol. 12, no. 4, pp. 239-262, 2002.

[146] E. De Clercq, "Antiviral drugs in current clinical use," Journal of Clinical Virology, vol. 30, no. 2, pp. 115-133, 2004.

[147] G. Campadelli-Fiume, F. Cocchi, L. Menotti et al., “The novel receptors that mediate the entry of herpes simplex viruses and animal alphaherpesviruses into cells," Reviews in Medical Virology, vol. 10, no. 5, pp. 305-319, 2000.

[148] R. Lippe, G. Guay, and R. Lippé, "Comprehensive characterization of extracellular HSV-1 virions," Journal of Virology, vol. 82, no. 17, pp. 8605-8618, 2008.

[149] B. D. Pilger, C. Cui, and D. M. Coen, "Identification of a small molecule that inhibits herpes simplex virus DNA polymerase subunit interactions and viral replication," Chemistry and Biology, vol. 11, no. 5, pp. 647-654, 2004.

[150] P. Digard, K. P. Williams, P. Hensley, I. S. Brooks, C. E. Dahl, and D. M. Coen, "Specific inhibition of herpes simplex virus DNA polymerase by helical peptides corresponding to the subunit interface," Proceedings of the National Academy of Sciences of the United States of America, vol. 92, no. 5, pp. 1456-1460, 1995.

[151] Y. Li, L. Zhao, S. Wang et al., "Identification of a novel NLS of herpes simplex virus type 1 (HSV-1) VP19C and its nuclear localization is required for efficient production of HSV-1," Journal of General Virology, vol. 93, no. 9, pp. 1869-1875, 2012. 


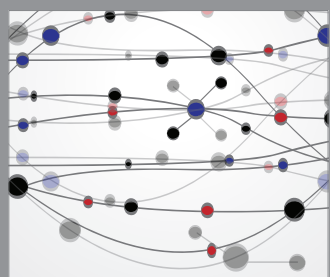

The Scientific World Journal
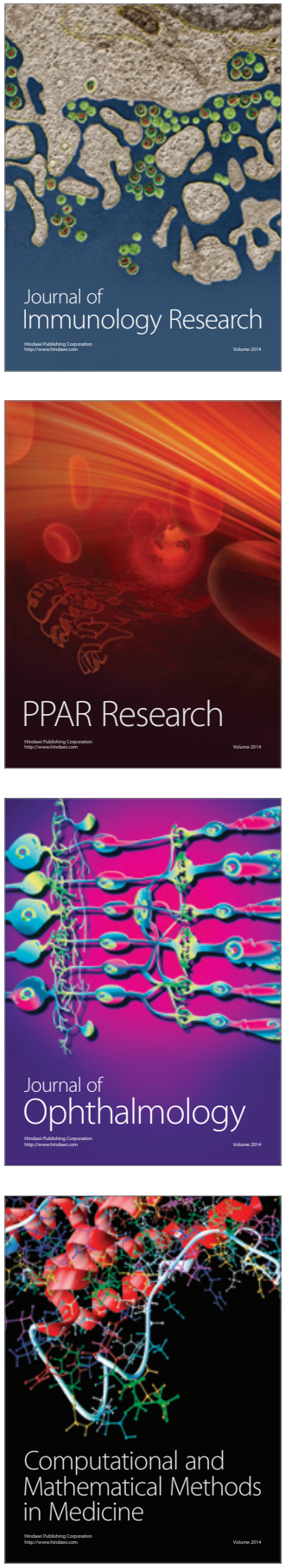

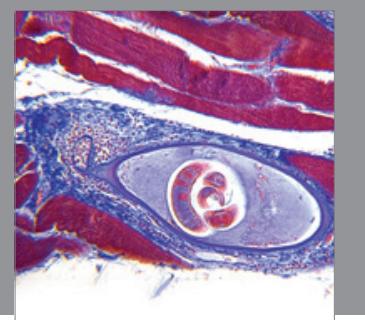

Gastroenterology

Research and Practice
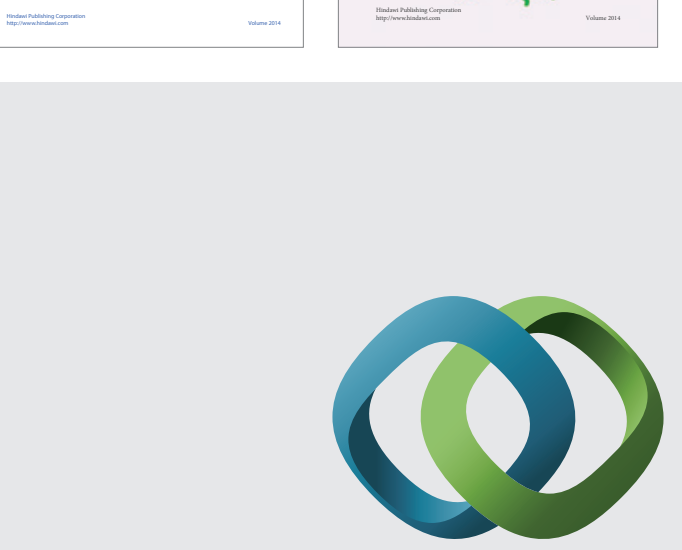

\section{Hindawi}

Submit your manuscripts at

http://www.hindawi.com
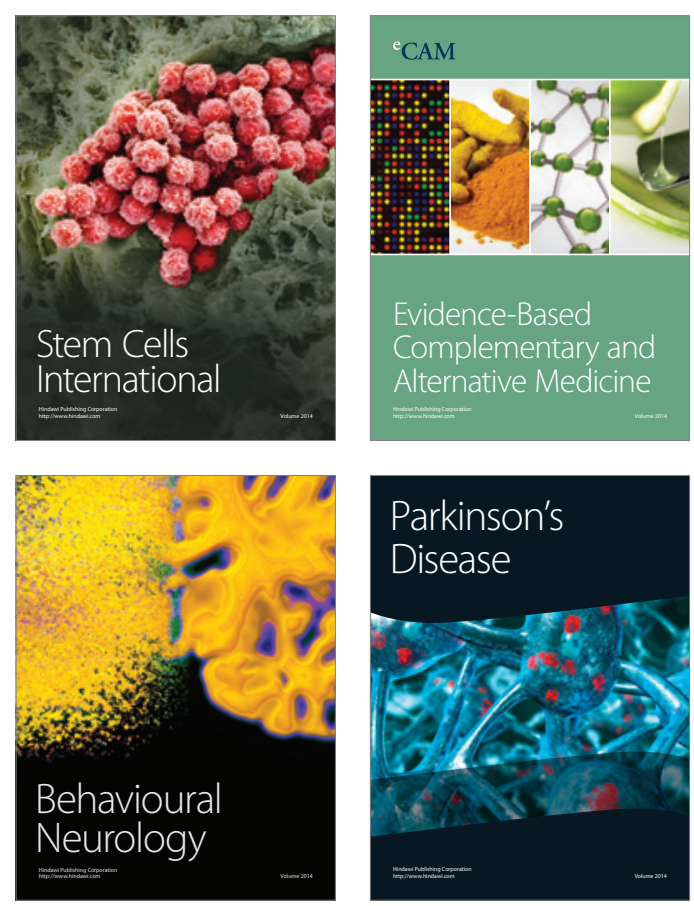

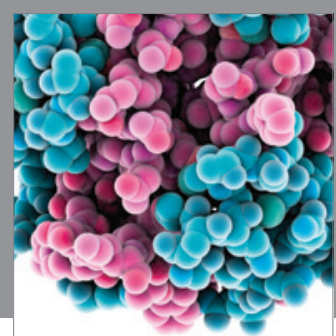

Journal of
Diabetes Research

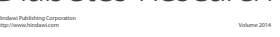

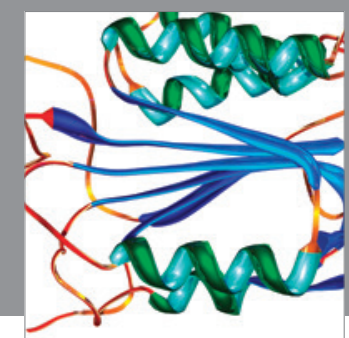

Disease Markers
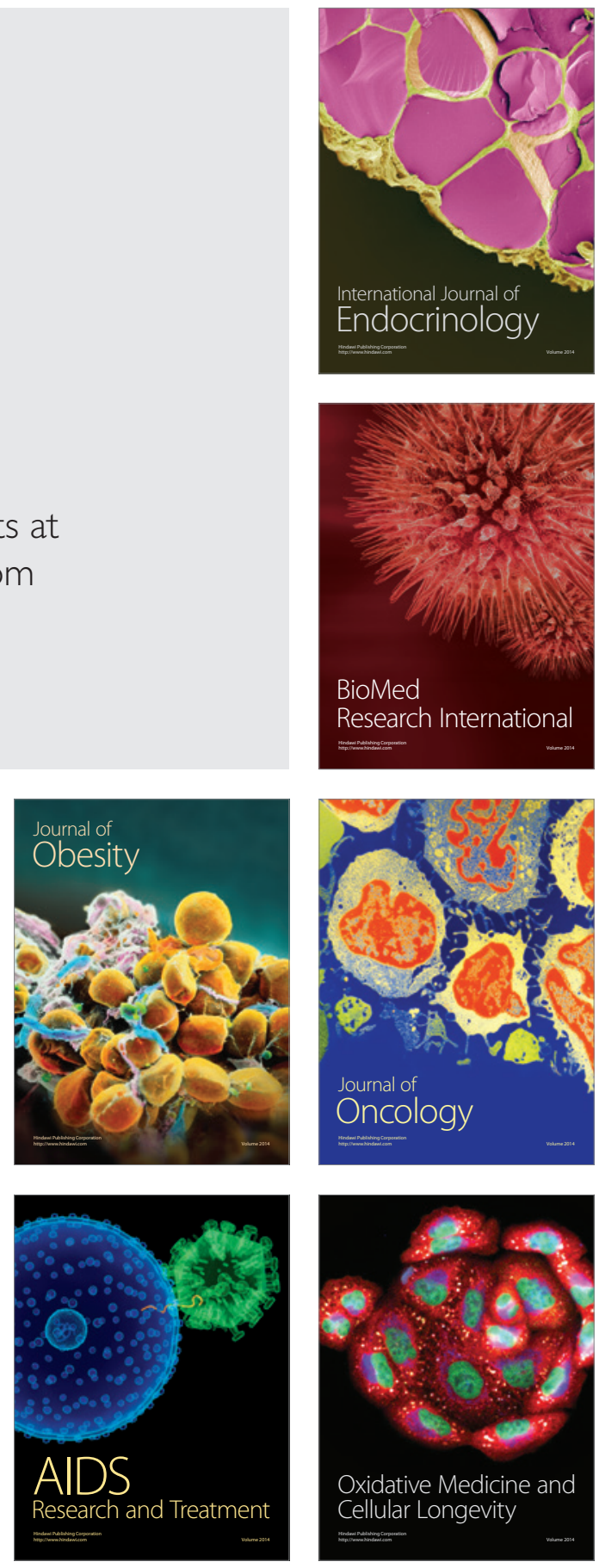